\title{
Do All Children with Guillain Barré Syndrome Need Immunotherapy?
}

\author{
Mahesh Kamate $^{1}$ (D) Mayank Detroja ${ }^{2}$ - Anuraag Nalla Reddy ${ }^{1}$
}

Received: 26 October 2018 / Accepted: 10 January 2019 / Published online: 18 January 2019

(C) Dr. K C Chaudhuri Foundation 2019

To the Editor: According to the published guidelines, patients with Guillain-Barré syndrome (GBS) who have Hughes disability score of 3 (inability to walk $>5 \mathrm{~m}$ unaided) or more in first 2-wk of illness need immunotherapy [Intra-venous immunoglobulin (IVIG) or plasma exchange (PE)] [1-3]. Immunotherapy is both expensive and invasive; not widely available also. There is paucity of good quality data on treatment of GBS in children. The adult guidelines may not hold good for children, as many even with higher disability score do improve without immunotherapy [4].

A retrospective review of medical records of 25 children with GBS that were managed in the last 6 mo was done. The mean age was $7.9(2.5-16)$ y. Mean duration to nadir of illness was 4.5 (2-14) d. Quadriparesis was commonest presenting symptom in $24(96 \%)$ patients, followed by paraesthesia in 19 $(76 \%)$, slurred speech in $8(32 \%)$, respiratory difficulty in 6 (24\%) and ataxia in $3(12 \%)$. Nerve conduction studies (done in 24 patients) showed axonal pattern in 19 (79.1\%) patients and demyelination in $5(20.8 \%)$.

Intervention in the form of immunotherapy was given to 6 patients (IVIG-4, PE-2) who had respiratory failure, bulbar palsy or rapidly progressive quadriparesis with loss of neck control within 48-72 h. Seventeen were treated symptomatically with physiotherapy and gabapentin. Among them, the Hughes disability score was $\geq 3$ in $76 \%$ patients at presentation and in $100 \%$ at nadir. One patient was lost to follow-up; 13 out of 16 cases showed complete recovery (Hughes 0/1) [Mean time for recovery-50 (20-90) d]. Two children received immunotherapy despite having Hughes score $<3$, because of parental request in the first week of illness. Outcome of these 2 children was similar to non-intervention group (Time to reach Hughes score of $0 / 1-60 d)$.

Mahesh Kamate

drmaheshkamate@gmail.com

1 Department of Pediatrics, KAHER's University's J N Medical College, Belgaum, Karnataka, India

2 Child Development Centre, KAHER's University's J N Medical College, Belgaum, Karnataka, India
In our study, 17 patients who had a Hughes score $\geq 3$, who satisfied the criteria for intervention according to the guidelines, were not treated with immunotherapy due to unaffordability but showed good recovery. Of these 17 patients, 8 patients who could sit independently and had nonprogression of disease by 5th-7th day of illness, were managed on OPD basis. So, a diagnosis of GBS does not always warrant IVIG or PE in all cases. Individualization of treatment is necessary specially in low income country like ours. Careful observation of patients for 1-2 wk of illness can avoid immunotherapy in many children. Children with respiratory failure, rapid progression of quadriparesis in $3-5 \mathrm{~d}$, or severe bulbar palsy can be considered for immunotherapy.

Authors' Contributions MK \& MD diagnosed the care and were involved in management of patients. ANR collected the data and drafted the paper. The final manuscript was approved by all the authors. MK will act as guarantor of the study.

\section{Compliance with Ethical Standards}

Conflict of Interest None.

Source of Funding None.

Publisher's Note Springer Nature remains neutral with regard to jurisdictional claims in published maps and institutional affiliations.

\section{References}

1. Hughes RA, Swan AV, Raphaël JC, Annane D, van Koningsveld R, van Doorn PA. Immunotherapy for Guillain-Barre syndrome: a systematic review. Brain. 2007;130:2245-57.

2. van Doorn PA, Ruts L, Jacobs BC. Clinical features, pathogenesis, and treatment of Guillain-Barré syndrome. Lancet Neurol. 2008;7: 939-50.

3. van den Berg B, Walgaard C, Drenthen J, Fokke C, Jacobs BC, van Doorn PA. Guillain-Barré syndrome: pathogenesis, diagnosis, treatment and prognosis. Nat Rev Neurol. 2014;10:469-82.

4. Gurses N, Uysal S, Cetinkaya F, Islek I, Kalaysi AG. Intravenous immunoglobulin treatment in children with guillain-Barre syndrome. Scand J Infect Dis. 1995;27:241-3. 